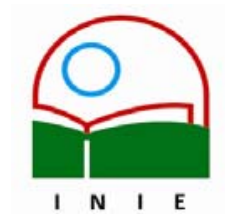

Universidad de Costa Rica

Facultad de Educación

Instituto de Investigación en Educación

ACTUALIDADES INVESTIGATIVAS EN EDUCACION

\title{
ANALYZING AN ORAL NARRATIVE USING DISCOURSE ANALYSIS TOOLS: OBSERVING HOW SPOKEN LANGUAGE WORKS
}

\begin{abstract}
César A. Navas Brenes ${ }^{1}$
Abstract: This article presents some tools of discourse analysis that are useful in analyzing and understanding different segments of an oral narrative. The main objective of this article is to explain and exemplify different concepts regarding the field of discourse analysis in order to study an oral anecdote in regard to danger of death recorded from a native speaker of English. It emphasizes the use of spoken texts (either scripts or recorded narrations) as primary sources of authentic features of the spoken language.
\end{abstract}

Key words: DISCOURSE ANALYSIS, IMPORTANCE OF ANALYZING SPOKEN TEXTS, NARRATIVE STRUCTURE, TRANSCRIPTIONS OF ORAL TEXTS

Resumen: Este artículo presenta algunas herramientas del campo del análisis del discurso las cuales son de gran utilidad a la hora de analizar y comprender diferentes segmentos de una narración oral. El principal objetivo es explicar y ejemplificar diferentes términos relacionados con el análisis del discurso con el objeto de estudiar una anécdota auténtica acerca de una experiencia muy cercana a la muerte. Dicha anécdota fue narrada por un hablante nativo de la lengua inglesa. Por medio de este artículo se espera enfatizar la importancia del uso de textos orales ya que contienen características importantes presentes en el lenguaje oral.

Palabras clave: ANÁLISIS DEL DISCURSO, IMPORTANCIA DE ANALIZAR TEXTOS ORALES, ESTRUCTURA DE NARRACIONES, TRANSCRIPCIONES DE TEXTOS ORALES

\section{Introduction}

Applied linguistics has always taken elements from different fields of study in order to provide language teachers and learners with effective tools for teaching ESL courses. The field of discourse analysis is one of those areas. For this reason, language instructors should get acquainted with discourse analysis tools. As a matter of fact, many language programs do not emphasize the essential characteristics of authentic spoken texts. This kind of texts

\footnotetext{
${ }^{1}$ Magíster en la Enseñanza del Inglés como Lengua Extranjera de la Universidad de Costa Rica; Bachiller en Inglés de la Universidad Internacional de las Américas, Profesor de la Escuela de Lenguas Modernas de la Universidad de Costa Rica.
}

Correo electrónico: cesarnavas@racsa.co.cr

Artículo recibido: 16 mayo del 2005

Aprobado: 20 de junio, 2005 
provides learners with important features of the spoken mode that do not necessarily take place in written language. In many language courses, instructors and learners take a lot of time analyzing examples of adapted written language rather than observing and studying samples of real spoken language. In fact, since language learners start acquiring a second language, they are exposed to a wide variety of written texts such as modified paragraphs, short stories, letters, excerpts from well-known newspapers or magazines, or essays. Unfortunately, in most cases, teachers do not take samples of spoken language into account in their ESL or ESL courses in order to help students understand different types of texts such as narratives or descriptions. What elements from discourse analysis can teachers use while using narratives? Can language teachers help students analyze and understand samples of spoken language? Are there any advantages in using spoken texts rather than written ones? It is widely known that there are many differences between the written and the spoken mode that need to be considered. As a matter of fact, these characteristics can derive in a better understanding of the target language. The main objectives of this article are to explain key concepts in the area of discourse analysis, and to demonstrate how they can be used in order to analyze an oral narrative recorded from a native speaker of English. The use of spoken texts such as oral narratives is more significant and appealing for students in order to comprehend how the spoken mode functions in real contexts. Unfortunately there are two difficulties in collecting oral texts. First, it is somewhat difficult to obtain appropriate narratives. To avoid this problem, the researcher should previously find out if his or her speakers have interesting or appealing stories that might arouse learners' interest. Secondly, transcribing oral stories is a time-consuming task. Some elements that make the preparation of scripts are the narrator's articulation and intonation patterns. Besides, the quality of the recording is crucial. 


\subsection{Review of Literature}

Before analyzing some of the characteristics of spoken language found in the subject's oral narrative, it is important to explain some terms such as discourse analysis and the notion of text. In his book Discourse Analysis for Language Teachers, McCarthy (1994, p. 5) clearly explains that "discourse analysis is concerned with the study of the relationship between language and the contexts in which is used." In other words, this branch of linguistics deals with how people construct their ideas in a cohesive and coherent way in order to communicate their message by means of written and spoken texts. In addition, Aitchison (1992, p. 97) has written that "when we use language, we do not necessarily do so in a random and unconstructed way. Both conversation and written texts have various devices for welding together miscellaneous utterances into a cohesive whole." Therefore, discourse analysis studies language in use taking into account important elements such as coherence (unity of the text) and cohesion (tools that tie together sentences, e.g. pronouns). For the purpose of this paper, the writer will emphasize spoken discourse based on a short oral narrative. Oral narratives contain plenty of meaningful elements that illustrate key discourse tools.

Discourse analysis depends on many components of language. Key elements such as lexicon, phonology, grammar, for instance, help linguists identify and interpret samples of spoken texts. McCarthy (1994, p. 9) argues that "discourse analysis is not entirely separate from the study of grammar and phonology, but discourse analysts are interested in a lot more than linguistic forms." This explains that discourse analysts focus on the study of the functions of the language and on how they are used in order to establish oral communication rather than analyzing the grammatical structures of the language. In order to understand the meaning of what is being said, the receiver (in this case the listener) appeals to the forms and functions of the language. Moreover, intonation patterns are also essential to infer the 
meaning of a specific idea unit; in other words, rising, sustained or falling intonation help the receiver decipher the meaning of a message or an oral text according to the context in which a certain utterance is used.

Another important term which needs to be explained is the notion of text. The word text can be defined as any type of linguistic or non-linguistic communication that can be interpreted in some way. In this case, the writer is going to use the definition of text given by Brown (1991, p. 11), that is, a text is "a verbal record of a communicative act." In this study, the researcher is going to use a sample of spoken data based on a transcription of an oral narrative delivered by an English native speaker. McCarthy reported that "with written texts, some of the problems associated with spoken transcripts are absent' (1994, p. 25). In other words, analyzing a spoken text is a difficult and time-consuming task since the speaker does not follow the same rules of organization that are frequently used when building up a text in written form. Consequently, spoken texts have a wide number of significant features that are not usually found in examples of written texts. These features may be influenced by some variables like the speaker's educational background, age, occupation, literacy in his or her target language, or even personality traits.

The spoken mode includes a wide variety of features that should be taken into account before analyzing an oral narrative. In terms of paralinguistic clues such as body language, facial expressions or proxemics (personal space), the speaker has more resources to convey meaning. In fact, some other features have to do with supra-segmental elements of language including sentences and word stress, rhythm, and intonation. Brown and Yule (1983, p. 4) state that "the speaker has available to him the full range of 'voice quality' effects (as well as facial expressions, postural, and gestural systems. Armed with these he can always override the effect of the words he speaks." If the interviewer or discourse analyst records the oral narrative using a video camera, those aspects easily observed in order to see how they affect reinforce meaning. However, in a script of the oral narrative the reader 
will not have the opportunity to see how those elements contribute to the message unless "a fine-grained phonetic transcription" is prepared (p. 9).

Besides these aspects that characterize the spoken mode, interruptions can take place at any time. Furthermore, the speaker can paraphrase his or her message by giving examples. He or she can also relate the content of the message to his or her listener's background knowledge. Also, he can adjust the speech or delivery. Brown and Yule (1983) point out that "in a spoken interaction the speaker has the advantage of being able to monitor his listener's minute-by-minute reaction to what he says" (р. 5). Therefore, both interlocutors can easily negotiate meaning or give feedback. The listener or receiver, who has a very active role in this communicative process, has more opportunities to comprehend what he or she is being said.

\section{Methodology}

\subsubsection{Subject}

The first step in analyzing some of the most peculiar features in a spoken text is to record an example of natural and spontaneous speech. The first task was to look for a narrator who was willing to tell an anecdote about a danger-of-death experience. This particular type of story is more likely to include many specific details (e.g. perturbations, coda, etc.) for further linguistic analysis. In this case, the researcher recorded a personal narrative in past tense told by a native speaker of English. This male narrator is a 37-year-old computer programmer who works in the area of telecommunications at Instituto Costarricense de Electricidad (I.C.E.). He is from the United States; however, he has lived in Grecia (Alajuela) for several years. It is important to mention that this person did not have any personal anecdote in regard to danger of death. For this reason, he referred to his brother's 
experience. His brother had a terrible traffic accident because he drove his car under the effects of the alcohol. The informant's brother lives in the United States now.

\subsubsection{Transcript of oral text}

Once the recording was made, the writer worked on the script of this oral text (see Appendix). This script includes a brief introduction preceding the story, as well as the resolution which is the part that indicates the end of a story. It is relevant to indicate that the interviewer should not constantly interrupt the informant while he or she is telling the anecdote because this will certainly affect the natural and spontaneous flow of ideas. Then, the linguistic transcription was analyzed putting into practice different tools provided by discourse analysis.

\section{ANALYSIS OF THE ORAL NARRATIVE}

\subsection{Characteristics of spoken texts included in the subject's oral narrative}

The spoken mode contains a wide selection of significant characteristics that differentiate it from written texts. The first general element has to do with the organizational pattern of oral texts. Regarding this component, Brown (1001, p.15) reported that "speech is less richly organized than written language, containing less densely packed information, but containing more interactive markers and planning fillers." Some of these features will be illustrated by lines taken from the transcription of the story. In EFL contexts, language learners must be aware of such differences in terms of lexicon in order to integrate those everyday expressions and discourse fillers into their productive vocabulary. Consider this group of idea units:

(a) (17) But ah anyway he was coming back ah one day from .. ah,

(18) I don't know why,

(19) but he likes to go drinking anyway,

(20) that's what alcoholics are basically, 
In excerpt (a), the speaker uses language without necessarily following a certain organizational pattern while telling a story. Perturbations or interruptions are relevant features of speech. The speaker tries to tell the events of the story, and at the end of line (17), he stops, and somehow generalizes about his brother's preference and behavior toward alcohol in people with this addiction. If language learners at a lower level are not exposed to authentic language, it may be quite difficult to understand such a disorganized flow of ideas as soon as they deal with longer pieces of discourse in real contexts. The second feature deals with formulaic expressions. Brown and Yule (1991) explain that in the spoken language "the speaker typically uses a good deal of rather generalized vocabulary: a lot of, got, do, thing, nice, stuff, place and things like that." This a key feature of spoken language that teachers should pay attention to. Besides, the same source mentions that "the speaker may produce a large number of prefabricated fillers: well, erm, I think, you know, if you see what I mean, of course, and so on (p.17)." The following group of idea units, lines (lines 39, 90, 42 and 05), contain prefabricated expressions, that is, examples of discourse fillers such as anyway, sort of, of course, or see what I mean that is highly common in the spoken mode rather than in written formal language.

(b) (39) ah A—nd the .. anyway what happened was he passed [???]

(90) ah And you know,

(42) and he sort of oh! Fortunately this was in the morning,

(05) that he was missing sort of a certain drug

Besides informal lexicon, the frequent use of single adjectives plays an important role in spoken language. In the following idea unit, the speaker describes what his brother's vehicle looked like before the car accident. In line (36) he uses a series of single adjectives (e.g., big, new, shinny and white) in order to let the receiver know what the external appearance of the car was before the incident. 
(c) (34) ah He had just bought himself a new car,

(35) it was a 1997 Thunder Bird,

(36) with big motor nice new shinny white car.

Finally, subordination is the fourth aspect exemplified in the script. In terms of spoken language, there is little subordination or hypotaxis: that is, spoken texts do not have an extensive use of subordinators in order to join clauses. Brown (1991) has pointed out the following:

In written language an extensive set of metalingual markers exists to mark relationships between clauses (that complementisers, when / while temporal markers, so-called 'logical connectors' like besides, moreover, however, in spite of, etc.), in spoken language the largely paratactically organized chunks are related by and, but, then and more rarely, if. (p. 16)

Therefore, consider this set of idea units:

(d) (74) he says the [???] the staples pulled out,

(75) and the wounds opened up,

(76) and his intestines came out,

(78) so he was holding his intestines in his hands,

In this excerpt, the speaker links the chunks of language using and, but he does not use other connectors such as while for instance. Coordination is, therefore, another important feature of the spoken mode. This is probably due to the 'economy of effort' that is present in spoken language.

\subsection{Identifying and classifying idea units in the subject's oral narrative}

The notion of idea unit plays a relevant role before trying to analyze oral narratives. Therefore, one of the tasks in order to analyze a spoken text is to divide it into its idea units; that is, the basic elements of consciousness that are used by the narrator to successfully transmit a message. Some experts have given the name of idea units to these spurts of language. These idea units can be identified taking into account intonation. Due to the fact 
that the subject spoke fast in some parts of his narration, rising or falling intonation was the key in order to identify idea units. Those idea units that finish with a rising intonation should be marked with a comma, while the ones that end with falling intonation are indicated with a period (Chafe, 1980). The same author (1980, p. 14) also suggests that "idea units are typically separated by at least a brief pause, often only the slight break in tempo marked here with two dots." In other words, pausing is an important factor that serves to identify idea units while transcribing an oral text. Consider the following examples of idea units present in the oral story:

(e) (08) ah A--nd so he doesn't have to work,

(09) he gets his check every month,

(10) so he has nothing else to do,

(11) but spend it at the bars.

In excerpt (e), intonation is the key to separate idea units. In lines 8,9 and 10, the dominant type of intonation at the end of the sentences is rising; that means that a comma is needed to separate them. In line 11 , on the contrary, the speaker uses falling intonation at the end of it; consequently, a period is used. In this example, each idea is expressed by a single clause. Consider the following examples and the idea units they are divided into:

(f) (30) and he says that he passed out

(31) because of the medication that he was on,

(32) but I think he passed out

(33) because of the medication and the alcohol he was on.

(g) (74) he says the [???] the staples pulled out,

(75) and the wound opened up,

(76) and his intestines came out,

(77) (interviewer) Oh my God!

(78) so he was holding his intestines in his hands,

In the two excerpts above, some of the idea units start with words such as and, but and so. This is another way to distinguish idea units, however, according to Chafe (1980) some other idea units begin with any other type of conjunction. 


\subsection{Centers of interest}

Narratives can be composed of idea units that can be classified in different ways. As Chafe $(1980$, p. 18) has suggested, "many narratives begin with the establishment of a setting." This deals with all the clues that help the listener locate in particular settings including distances or places. In fact, the subject's story does begin with clear examples in terms of arrangement of the spatial orientation which helps the receiver or listener understand the narrative. This sequence of idea units illustrates this characteristic:

(h) (23) Anyways he was coming back from a bar,

(25) If you've been in the United States,

(26) But that .. the roads there .. the main roads like the freeways have usually two or three lanes ah on one side,

(27) And two or three lanes separated on the other side,

(28) And anyway he was (he was) going about sixty miles an hour about a hundred kilometers an hour underneath the bridge,

Although most narratives begin with idea units that establish the setting of the story, it is common to find some spatial orientation throughout the oral text.

(i) (54) and they air-lifted him to a hospital in Seattle,

(55) this occurred in [???]

(56) which is about thirty miles South from Seattle,

(j) (42) and he sort of! fortunately this was in the morning,

The idea units above do establish spatial orientation although they do not take place at the beginning of the story. They provide the receiver with relevant information related to the main events of the narrative. Another instance of orientation that is found in the text (line 42) is called temporal orientation. As its name suggests, it includes expressions that indicate the time in which specific events or actions take place.

A third aspect found in many narratives is the introduction and characterization of the people involved in the story. Even though this introduction does not belong to the main events of the narrative, they provide the audience with key data regarding interesting aspects 
of the participants' lives. The informant's narration is a good example of this feature since he gives a complete explanation of some essential and interesting details of his brother's life. The following group of idea units exemplifies this fact:

(k) (1) He actually he got a medical discharge,

(2) they determined that he was at that point,

(3) when he is in the military,

(4) that he had a chemical imbalance in his head,

(5) that he was missing sort of a certain drug

(6) that helped him maintain stability;

(7) so ever since then, he's been on a medical pension from the military, from the army, the air force.

(8) Ah A-nd so he doesn't have to work.

(9) He gest his check every month,

(10) So he has nothing else to do,

(11) But spends it at the bars.

This introductory orientation is part of a segment of the narrative called background, that is, the portion of the story that gives additional material which allows the listener to evaluate the main events of the plot. By paying attention to the explanation above, the receiver can learn many details about the subject's life before the speaker moves on to the most important events of the story.

In transcribing an oral narrative, the notion of center of interest must be taken into account. A center of interest can be defined as a group of idea units related to a certain event or topic. According to Chafe $(1980$, p. 29) a center of interest "often includes a set of events leading to a goal." While in the written mode punctuation marks are used to separate sentences, in the spoken mode the listener should focus on those groups of lines that relate to single topics. This is particularly relevant when one tries to transcribe an oral narrative. In some cases, these centers of interest might be clearly indicated by coordinating and/or subordinating conjunctions. As a matter of fact, in this oral narrative most centers of interest include coordinating conjunctions such as and, but and/or so. In some idea units, relative pronouns may also used. 
(I) (52) ah A--nd .. they had to ah the medics,

(53) the medical unit that arrived there had to get him out of the car,

(54) and they air-lifted him to a hospital in Seattle,

(55) this occurred in [???]

(56) which is about thirty miles South from Seattle,

(57) and air-lifted him there.

The center of interest above consists of a series of idea units which are mostly linked by the conjunction and. The main goal of this group of idea units is to tell how the subject's brother was rescued by the paramedics and taken to the hospital by helicopter. Due to the fact that lines 52-57 have a specific goal, they form one single center of interest.

\subsection{Perturbations of oral narratives}

When one listens to an oral narrative, the audience has to cope with frequent interruptions or insertions of extra ideas. Chafe $(1980$, p.33) has pointed out that "speakers do not achieve the expression of a series of idea units without some trouble; natural speech exhibits a variety of perturbations in this process." In other words, a perturbation is a significant feature of spoken language because of its spontaneity. In the subject's oral narrative, many instances of perturbation can be found. The first perturbation takes place at the beginning of the narrative. Consider these excerpts:

(m)(17) But ah anyway he was coming back ah one day from .. ah,

(18) don't know why

(19) But he likes to go drinking anyway,

(20) That's what alcoholics are basically,

(21) He doesn't he wouldn't invent it as a kind of problem,

(22) But I think he does.

Notice how in line 17 the narrator starts telling the main events of the story and then he suddenly stops and interrupts the narrative to refer to his brother's drinking problem. Other kinds of perturbations found throughout this narrative are postponements of the plot in order 
to add supporting details to the story. That is, some of the key idea units of the story are described later in the plot. In addition, there is a second type of perturbation in the text which is illustrated in the following group of idea units:

(n) (23) Anyways he was coming back from a bar,

(24) A—nd he was oh! I don't know

(25) If you've been in the United States,

(26) But that .. the roads there .. the main roads like the freeways have usually two or three lanes ah on one side,

(27) And two or three lanes separated on the other side,

(28) And anyway he was (he was) going about sixty miles an hour about a hundred kilometers an hour underneath the bridge,

In this case the speaker interrupts himself after line 23 to produce lines $24-27$. He includes some supporting information on what the U.S. highways look like. However, he never abandons the idea he has been focusing on since the beginning of the story in line 23 , and he goes back to the main events in line 28. An interesting detail is the fact that he uses non-past verbs instead of past tense in these lines (24-27). A possible explanation for this deals with the notions of the foreground and background information of oral narratives. As BardoviHarlig (1992) explains, the foreground refers to the skeleton of the narrative, that is, the main actions that constitute its plot. On the contrary, the background information provides additional material to the foreground. Non-past verbs are frequently used in the background while past tense is mostly used in the foreground.

\subsection{Chronological elements in Mark Earle's oral narrative}

Chafe explains that narratives are composed of chronological or structural elements such as "abstract, orientation, and resolution" (1980). The first element is called abstract. It is defined as a short summary of the whole story usually told in a few idea units. There is no abstract in the informant's narrative because he starts telling the story as soon as he finishes 
his introduction. The second part of the narrative is the orientation. It establishes spatial and temporal orientation. The spatial and temporal orientation has been previously exemplified. In addition, this narrative does include a very complete introduction before the speaker starts telling his brother's danger-of-death experience. This short introduction is followed by the complex events that tell the action of the story. Another element is the resolution, that is, how the story reaches its end. These lines illustrate this concept:

(0) (84) $\mathrm{He}$ is forty years old,

(85) and he has to walk real slowly,

(86) he got ah and they put some pins in one of his leg,

(87) and he has to go back for his physical therapy on a regular basis,

(88) ah and it was because of this one stupid mistake,

(89) ah one event .. one life-boltering event.

The excerpt above includes the end of the narrative. This resolution tells the receiver that the most important events of the story are coming to an end (lines 86-89). It is interesting to notice that although the plot of this narrative consists of the serious car accident Mark's brother suffered, the narrator also refers to follow-up events that took place at the hospital after he was operated on. Once the resolution is given, the speaker comes up with a brief evaluation of his brother's actions. He ends his story by saying that in spite of the dangerous accident he had due to the influence of alcohol, his brother has not changed his behavior.

\section{CONCLUSION}

There are a few aspects that should be taken into account in order to fully understand the important of discourse analysis and its implication in language teaching. For example, language teachers can apply different concepts from the area of discourse analysis (e.g., foreground, background, centers of interest, and background knowledge) on the teaching of certain skills such as reading or listening comprehension. Therefore, an important question 
comes up: what can ESL teachers learn from analyzing the authentic language of oral narratives? On one hand, language instructors should use real-life texts in their lessons because they include valuable samples of natural and spontaneous speech from native and non-native speakers of the target language. Learners should be also exposed to real texts rather than traditional or fixed written or oral texts that lack-in some cases- idiomatic expressions and discourse fillers. As a matter of fact, Bardovi-Harlig (1997) has explained that learners are more likely to associate the notions of form-meaning-use in spoken texts than in descontextualized grammar books. Using spoken texts such as a short transcription of narratives, for instance, would provide learners with a great opportunity to focus on useful aspects of the spoken mode (e.g., fillers, formulaic phrases, and or contractions). Therefore, the field of discourse analysis provides instructors with key tools in order to show learners how spoken language works in authentic contexts.

\section{REFERENCES}

Aitchison, J. (1992). Teach Yourself Linguistics. Chicago: NTC Publishing Group.

Bardovi-Harling, K. (1992). The Telling of a Tale: Discourse Structure and Tense Use in Learner's Narratives. Pragmatics and Language Learners. Monograph Series, Vol 3. Urbana, IL: University of IL, DEIL.

Brown, Gillian, and Yale, G. (1991). Discourse Analysis. Cambridge: Cambridge University Press.

Chafe, L. W. (ed.). (1980). The Pear Stories: Cognitive, Cultural and Linguistic Aspects of Narrative Production. Norwood, N. J.: Ablex Publishing Corp.

McCarthy, M. (1994). Discourse Analysis for Language Teachers. Cambridge: Cambridge University Press. 


\section{APPENDIX}

\section{TRANSCRIPT OF ORAL NARRATIVE}

(1) He actually he got a medical discharge,

(2) they determined that he was at that point,

(3) when he is in the military,

(4) that he had a chemical imbalance in his head,

(5) that he was missing sort of a certain drug

(6) that helped him maintain stability;

(7) so ever since then, he's been on a medical pension from the military, from the army, the air force.

(8) Ah A-nd so he doesn' t have to work.

(9) He gets his check every month,

(10) So he has nothing else to do,

(11) But spends it at the bars.

(12) And you know,

(13) He sells different cars back and forth.

(14) He is not supposed to drink, by the way

(15) Because of his medication,

(16) And the medication and the alcohol don't mix.

(17) But ah.. anyway he was coming back ah one day from..ah,

(18) I don't know why

(19) But he likes to go drinking anyway,

(20) That's what alcoholics are basically,

(21) He doesn't he wouldn't invent it as a kind of problem,

(22) But I think he does.

(23) Anyways he was coming back from a bar,

(24) A-nd he was oh! I don't know

(25) If you've been in the United States,

(26) But that .. the roads there .. the main roads like the freeways have usually two or three lanes ah on one side, 
(27) And two or three lanes separated on the other side,

(28) And anyway he was (he was) going about sixty miles an hour about a hundred kilometers an hour underneath the bridge,

(29) Where he passed out,

(30) And he says that he passed out

(31) Because of the medication that he was on,

(32) But I think he passed out

(33) Because of the medication and the alcohol he was on.

(34) Ah He had just bought himself a new car,

(35) It was a 1997 Thunder Bird,

(36) With big motor nice new shinny white car.

(37) (interviewer) very fancy

(38) ah very fancy

(39) ah A-- nd .. anyway what happened was as he passed [???]

(40) he passed the bridge,

(41) he passed out,

(42) and he sort of oh! Fortunately this was in the morning,

(43) there were not a lot of cars,

(44) but he sort of left the road,

(45) went through a ditch,

(46) went through a fence,

(47) a--nd kept going about two hundred yards,

(48) and ah he hit a tree off the side of the road,

(49) ah totally destroyed the car.

(50) I saw a picture of it,

(51) it was just a mangled mess.

(52) ah A--nd .. they had to ah the medics,

(53) the medical unit that arrived there had to get him out of the car,

(54) and they air-lifted him to a hospital in Seattle,

(55) this occurred in [???]

(56) which is about thirty miles South from Seattle,

(57) and air-lifted him there.

(58) And they were sure

(59) he was going to make it. 
(60) He was in a critic-care unit for a couple of weeks,

(61) ah a-nd he had several internal injuries,

(62) they had to do an abdominal surgery on him.

(63) And ah one of the things that happened to him

(64) as he was recovering,

(65) he thought that he was wrong

(66) until he got up and started walking around,

(67) while he had a surgery in his stomach

(68) that was put together with staples,

(69) it was a surgery that was stapled,

(70) and it was kind of weak,

(71) ah and I think this is actually kind of funny

(72) that scared the hell out of him,

(73) when he was getting up,

(74) he says the [???] the staples pulled out,

(75) and the wound opened up,

(76) and his intestines came out,

(77) (interviewer) Oh my God!

(78) so he was holding his intestines in his hands,

(79) and ah he says it was one of those frightening things that he has ever seen,

(80) (interviewer) and that happened at the hospital

(81) that was at the hospital yeah (that was at the hospital)

(82) this was actually about two weeks trying to ah recover from the accident

(83) but the .. he ah [???]

(84) He is forty years old,

(85) and he has to walk real slowly,

(86) he got ah and they put some pins in one of his leg,

(87) and he has to go back for his physical therapy on a regular basis,

(88) ah and it was because of this one stupid mistake,

(89) ah one event .. one life-boltering event.

(90) ah And you know,

(91) there is something despite of this,

(92) he hasn't changed on that much, 
(93) I mean he still does the same thing,

(94) he is not .. he still goes drinking,

(95) he's not working in place.

(96) ah .. So l'm kind of surprised actually and kind of disappointed

(97) because this was a good opportunity for him to to wake up

(98) let's say

(99) Oh my God! You know,

(100) this is serious! 